DOI: 10.52362/jmijayakarta.v1i2.446

\title{
PERANCANGAN APLIKASI PENGGAJIAN KARYAWAN BERBASIS WEB MENGGUNAKAN FRAMEWORK CODEIGNITER PADA PO ARISTA TEHNIK JAKARTA
}

\author{
Reza Fahlevi ${ }^{1}$, Zulhalim $^{2}$, Asih Septia Rini ${ }^{3}$ \\ Program Studi Sistem Informasi ${ }^{1}$, Program Studi Teknik Informatika ${ }^{2}$, Program Studi Manajemen ${ }^{3}$ \\ STMIK Jayakarta ${ }^{1}$, STMIK Jayakarta ${ }^{2}$, STIE Jayakarta ${ }^{3}$ \\ 16562006@stmik.jayakarta.ac.id ${ }^{1}$, zulhalim@stmik.jayakarta.ac.id ${ }^{2}$, Asih@Septiarini.com ${ }^{3}$
}

\begin{abstract}
ABSTRAK
Arista Tehnik Jakarta merupakan perusahaan perorangan yang bergerak dibidang jasa pembuatan AC Ducting pada bangunan gedung. Arista Tehnik Jakarta dalam mengolah data penggajian karyawan masih menggunakan cara manual/konvensional, yaitu mencatat pada pembukuan sehingga seringkali terjadi kesalahan pada menghitung gaji karyawan. Dalam menghitung gaji karyawan bisa berakibat fatal jika terjadi kesalahan dan bisa berpengaruh pada pembuatan laporan penggjian. Sistem penggajian secara manual/konvensional sudah kurang mampu memberikan manfaat yang memadai bagi penghitungan gaji karyawan. Dengan sistem penggajian yang baik sangat dibutuhkan oleh setiap perusahaan yang sudah memiliki banyak karyawan. Perusahaan yang memiliki banyak karyawan pasti membutuhkan sistem penggajian yang dapat memudahkan untuk membayar gaji secara tepat dan efisien. Metode yang digunakan dalam penelitian ini yaitu dengan melakukan observasi, wawancara, studi pustaka, perancangan sistem informasi dilanjutkan dengan pembangunan sistem informasi dan selanjutnya adalah uji coba. Hasil dari penelitian ini adalah menghasilkan sistem informasi penggajian yang terkomputerisasi yang diberikan kemudahan dalam memberikan informasi data penggajian seperti informasi data karyawan, data jabatan \& data penggajian. Pada Sistem Informasi Data Penggajian menggunakan UML (Unified Modeling Language), pembuatan program menggunakan framework CodeIgniter, dan MySQL untuk pengolahan basis data. Setelah peneliti lalu membuat Sistem Informasi Penggajian, prosedur kerja dapat lebih mudah bagi perusahaan Arista Tehnik Jakarta.
\end{abstract}

Kata kunci: Arista Tehnik Jakarta, Penggajian Karyawan, CodeIgniter.

Abstract: Arista Tehnik Jakarta is an individual company engaged in manufacturing services for AC ducting in buildings. Arista Tehnik Jakarta in processing employee payroll data still uses the manual / conventional method, which is taking notes on bookkeeping so that errors often occur in calculating employee salaries. Calculating employee salaries can have fatal consequences if something goes wrong and it can affect the preparation of payroll reports. The manual / conventional payroll system is not able to provide adequate benefits for calculating employee salaries. With a good payroll system, every company that already has many employees is very much needed. Companies that have many employees definitely need a payroll system that can make it easier to pay salaries appropriately and efficiently. The method used in this research is by making observations, interviews, literature studies, designing information systems followed by the development of information systems and then testing. The result of this research is to produce a computerized payroll information system that provides convenience in providing payroll data information such as employee data information, job data and payroll data. In the Payroll Data Information System using UML (Unified Modeling Language), programming using the CodeIgniter framework, and MySQL for database processing. After the researcher then created a Payroll Information System, the work procedure could be easier for Arista Tehnik Jakarta.

Keywords: Arista Tehnik Jakarta, Employee Payroll, CodeIgniter.

Ciptaan disebarluaskan di bawah Lisensi Creative Commons Atribusi 4.0 Internasional.

http://journal.stmikjayakarta.ac.id/index.php/JMIJayakarta 
DOI: $10.52362 /$ jmijayakarta.v1i2.446

\section{PENDAHULUAN}

\subsection{Latar Belakang Masalah}

Pada saat ini Teknologi Informasi (TI) berkembang dengan pesat. Perkembangan yang berlangsung dengan cepat, baik dari perangkat keras (hardware) atau perangkat lunak (software). Dengan teknologi informasi dapat membantu pekerjaan diberbagai banyak bidang lainnya, dan meningkatkan kinerja, sehingga berbagai perkerjaan dapat diselesaikan dengan cepat, tepat dan akurat, sehingga dapat meningkatkan produktivitas. Kelebihan dari Teknologi Informasi ini, semestinya dimanfaatkan oleh perusahaan untuk mengelola beragam aktivitas dengan baik, terencana, dan terdokumentasi dengan maksimal.

Setiap perusahaan membutuhkan banyak faktor untuk bisa menjalankan usahanya dengan tepat. Faktor Sumber Daya Manusia (SDM) dalam hal ini, sangat penting bagi setiap perusahaan yang akan menjalankan usahanya. Karyawan adalah orang yang dipekerjakan pada perusahaan (pemberi kerja), melakukan pekerjaan sesuai dengan perjanjian kerja baik tertulis maupun tidak tertulis. Peran karyawan dalam mengerjakan tugasnya sangat membantu tercapai tujuan perusahaan. Agar tercapai tujuan perusahaan, karyawan membutuhkan balas jasa atau bayaran yang sudah disepakati diawal sebelum memulai bekerja, agar menjadi memacu kinerja karyawan. Dengan menggunakan sistem penggajian yang memadai, maka proses penggajian bisa dilakukan atau dilaksanakan dengan sistematis dan sehingga tidak akan terjadi kesalahan dalam prosedur penggajian.

Dengan sistem penggajian yang baik sangat dibutuhkan oleh setiap perusahaan yang sudah memiliki banyak karyawan. Perusahaan yang memiliki banyak karyawan pastinya membutuhkan sistem penggajian yang dapat memudahkan untuk membayar gaji secara tepat dan efisien. Dengan perkembangan Teknologi Informasi (TI) yang semakin pesat, sistem penggajian secara manual/konvensional dirasa sudah kurang mampu memberikan manfaat yang memadai bagi penghitungan gaji karyawan. Beberapa perusahaan kini mulai banyak beralih menggunakan sistem yang berbasis komputerisasi.

Arista Tehnik Jakarta merupakan perusahaan perorangan yang bergerak dibidang jasa pembuatan AC Ducting pada bangunan gedung. AC Ducting merupakan penyejuk ruangan yang dapat menyampaikan sirkulasi udara dengan bantuan blower atau fan unit.

Menurut penulis lakukan dengan cara observasi dan wawancara, Arista Tehnik Jakarta dalam mengolah data penggajian karyawan masih menggunakan cara manual/konvensional, yaitu mencatat pada pembukuan sehingga seringkali terjadi kesalahan pada menghitung gaji karyawan.

Dalam menghitung gaji karyawan bisa berakibat fatal jika terjadi kesalahan dan bisa berpengaruh pada pembuatan laporan keuangan. Ketika sekretaris membuat laporan keuangan mengalami kesulitan, karena harus melihat data pada pembukuan, lalu mengolahnya menggunakan Microsoft Office Excel sehingga untuk mendapatkan hasil laporan gaji yang diterima oleh karyawan ataupun hasil laporan bulanan penggajian, membutuhkan waktu untuk dapat memperhitungkan-nya, dan sangat beresiko kehilangan data karena tidak memiliki database untuk penyimpanan data penggajian tersebut. Dengan demikian penelitian ini diadakan agar bisa membantu dalam menyelesaikan permasalahan pada Sistem Informasi Penggajian Karyawan pada PO Arista Tehnik Jakarta.

\subsection{Identifikasi Masalah}

Dari pembahasan latar belakang diatas dapat disimpulkan identifikasi masalahnya, sebagai berikut:

1. Dengan penggajian manual bisa seringkali terjadi kesalahan.

2. Untuk menghitung gaji karyawan membutuhkan waktu yang cukup lama.

3. Laporan gaji bisa hilang karena tidak disimpan ke database.

\subsection{Rumusan Masalah}

Adapun permasalahan yang akan dibahas dalam tulisan ini adalah sebagai berikut:

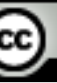


DOI: 10.52362/jmijayakarta.v1i2.446

1. Bagaimana sistem absensi saat ini dapat berjalan didalam perusahaan?

2. Bagaimana membuat sistem informasi penggajian pada PO Arista Tehnik Jakarta?

3. Bagaimana merancang sistem informasi penggajian yang efektif dan efisien?

\section{METODE DAN MATERI}

Bagian ini memberikan pedoman bagi penulis tentang elemen-elemen penulisan dan ilustrasi saat menyiapkan naskah.

\subsection{Pengertian Perancangan Sistem}

Perancangan adalah setiap rancangan harus memenuhi kebutuhan penggunanya dan dapat berfungsi dengan baik, fungsi timbul sebagai akibat dari adanya kebutuhan manusia dalam usaha untuk mempertahankan serta mengembangkan hidup dan kehidupannya di alam semesta ini. [1]

Sistem merupakan seperangkat elemen yang saling bergantung yang bersama-sama mencapai tujuan tertentu. Dimana sistem harus memiliki organisasi, hubungan timbal balik, integrasi dan tujuan pokok. [2]

Perancangan sistem adalah proses pengembangan spesifikasi sistem baru berdasarkan hasil rekomendasi analisis sistem. Dalam tahap perancangan, tim kerja desain harus merancang spesifikasi yang dibutuhkan dalam berbagai uraian mengenai input, proses, dan output dari sistem yang diusulkan, [3]

Berdasarkan beberapa pendapat di atas dapat ditarik kesimpulan bahwa definisi dari perancangan adalah penggambaran dari sebuah perencanaan yang berisi beberapa elemen yang diterapkan menjadi sebuah kesatuan sistem yang utuh serta dapat difungsikan dan diimplementasikan.

\subsection{Pengertian Sistem Informasi}

Sistem Informasi adalah kumpulan elemen yang saling berhubungan satu sama lain yang membentuk satu kesatuan untuk mengintegrasikan data, memproses dan menyimpan serta mendistribusikan informasi.[4]

Sistem informasi adalah cara terorganisir untuk mengumpulkan, memasukkan, memproses data serta menyimpan, mengelola, mengontrol, dan melaporkannya sehingga dapat membantu organisasi dalam mencapai tujuan.[5]

\subsection{Pengertian Penggajian}

Penggajian adalah sistem yang digunakan oleh perusahaan untuk memberikan upah dan gaji kepada karyawannya atas jasa-jasa yang mereka berikan.[6]

Gaji adalah sejumlah pembayaran kepada karyawan yang diberi tugas administratif dan manajemen yang biasanya ditetapkan secara bulanan. Sedangkan upah merupakan imbalan yang diberikan kepada buruh yang melakukan pekerjaan kasar dan lebih banyak mengandalkan kekuatan fisik, jumlah pembayaran upah biasanya ditetapkan secara harian atau berdasarkan unit pekerjaan yang diselesaikan.

\subsection{Website}

Website atau web adalah sekumpulan halaman yang berisi informasi dalam bentuk data digital baik berupa text, gambar, video, audio, dan animasi lainnya yang disediakan melalui jalur koneksi internet.[5]

Web adalah salah satu aplikasi yang berisikan dokumen-dokumen multimedia (teks, gambar, suara, animasi, video) di dalamnya yang mengunakan protokol HTTP (hypertext transfer protokol) dan untuk mengakses menggunakan perangkat lunak yang disebut browser.[7] Fungsi website diantaranya :

1. Media Promosi

2. Media Pemasaran 
DOI: $10.52362 /$ jmijayakarta.v1i2.446

3. Media Informasi

4. Media Pendidikan

5. Media Komunikasi

\subsection{MySQL}

MySQL (My Structure Query Language) adalah adalah aplikasi atau sistem untuk mengelola database atau manajemen data. Untuk menyimpan segala informasi kekomputer mengunakan data. MYSQL bertugas mengatur dan mengelola data-data pada database, selain itu MYSQL dikenal sebagai sistem yang efisien dan reliable, proses query cepat dan mudah, sehingga cocok digunakan untuk aplikasi berbasis web.[7]

Dengan menggunakan MySQL kita dapat melakukan hal-hal berikut:

1. Memodifikasi struktur database .

2. Mengubah, mengisi, menghapus isi database

3. Mentransfer data antara database yang berbeda

\subsection{PHP}

PHP (Hypertext Prepocessor) merupakan bahasa pemrograman berbasis server-side yang dapat melakukan parsing script php menjadi script web sehingga dari sisi client menghasilkan suatu tampilan yang menarik.[5]

PHP adalah PHP (Hypertext Preprocessor) adalah bahasa pemrograman web berbasis server (server slide) yang mampu memparsing kode PHP dari kode dengan ekstensi PHP sehingga menghasilkan tampilan website yang dinamis disisi client.[4]

\subsection{Framework}

Framework adalah kumpulan intruksi-intruksi yang dikumpulkan dalam class dan functionfunction dengan fungsi masingmasing untuk memudahkan developer dalam memanggilnya tanpa harus menuliskan syntax program yang sama berulang-ulang serta dapat menghemat waktu.[8]

\subsection{CodeIgniter}

CodeIgniter adalah Sebuah framework php yang bersifat open source dan menggunakan metode MVC (Model, View, Controller) untuk memudahkan developer atau programmer dalam membangun sebuah aplikasi berbasis web tanpa harus membuatnya dari awal.[8]

Framework Codeigniter dikembangkan oleh Rick Ellis, CEO Ellislab, Inc. kelebihan dari framework codeigniter jika dibandingkan dengan framework lain adalah sebagai berikut :

1. Gratis (Open-Source) Kerangka kerja Codeigniter memiliki lisensi dibawah Apache/BSD open-source sehingga bersifat bebas atau gratis.

2. Berukuran kecil Ukuran yang kecil merupakan keunggulan tersendiri jika dibandingkan framework lain yang berukuran besar dan membutuhkan resource yang besar dan juga dalam eksekusi maupun penyimpanannya.

3. Menggunakan konsep M-V-C Codeigniter merupakan konsep M-V-C (ModelViewController) yang memungkinkan pemisahan antara layer application-logic dan presentation. Dengan konsep ini kode PHP, query Mysql, Javascript dan CSS dapat saling dipisah-pisahkan sehingga ukuran file menjadi lebih kecil dan lebih mudah dalam perbaikan kedepannya atau maintenance.

\subsection{Unified Modeling Language (UML)}

UML (Unified Modeling Language) adalah salah satu standar bahasa yang banyak digunakan di dunia industri untuk medefinisikan requirement, membuat analisis dan desain, serta menggambarkan arstitektur dalam pemograman berorientasi objek.[9]

UML muncul karena adanya kebutuhan pemodel visual untuk menspesifikasikan, menggambarkan, membangun dan dokumentasi dari sistem perangkat lunak. 
DOI: 10.52362/jmijayakarta.v1i2.446

UML mempunyai beberapa atau sejumlah elemen grafis yang bisa dikombinasikan menjadi diagram. Diagram tersebut akan menggambarkan atau mendokumentasikan beberapa aspek dari sebuah sistem.

\section{HASIL DAN PEMBAHASAN}

\subsection{Use Case yang Diusulkan}

Proses penggajian karyawan yang diusulkan pada PO Arista Tehnik Jakarta mengunakan Use Case Diagram sebagai berkut :

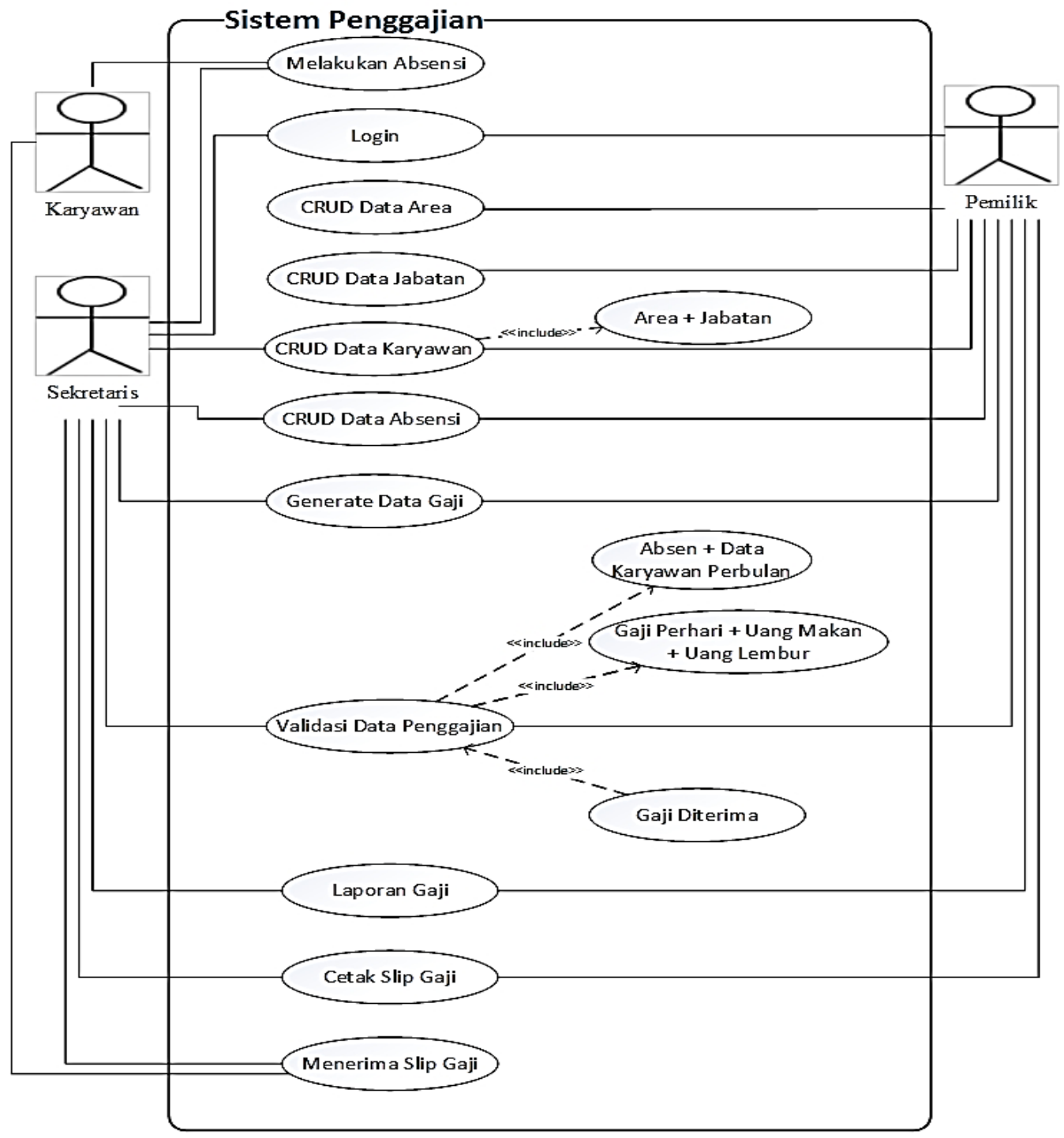

Gambar 1 Use Case yang Diusulkan 


\subsection{Flowchart Sistem Sistem yang Diusulkan}

DOI: 10.52362/jmijayakarta.v1i2.446

Proses penggajian karyawan yang diusulkan pada PO Arista Tehnik Jakarta mengunakan Flowchart sebagai berkut :

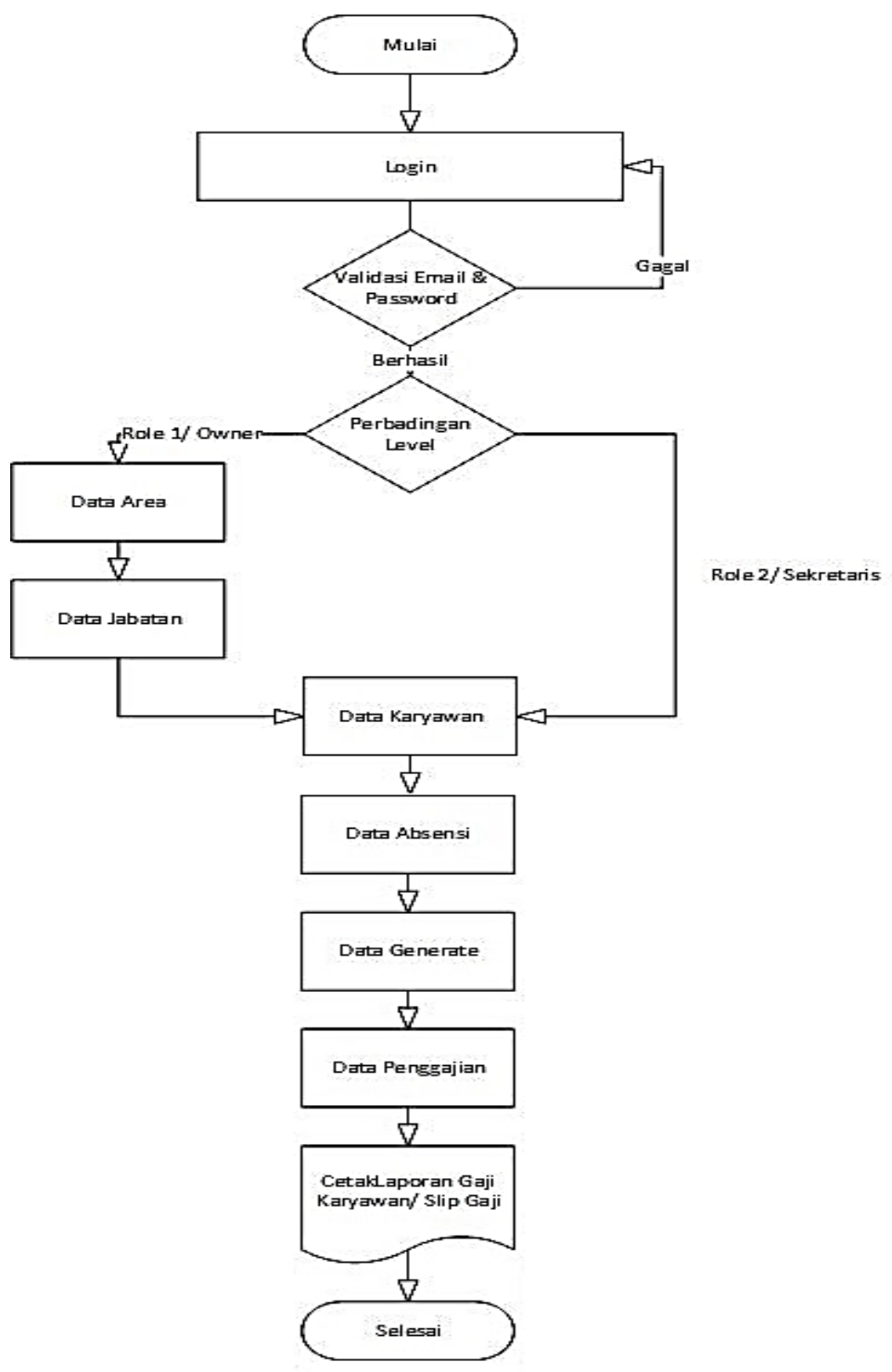

Gambar 2 Flowchart Sistem Sistem yang Diusulkan 


\subsection{Implementasi Halaman Login}

DOI: $10.52362 /$ jmijayakarta.v1i2.446

\section{Arista Tehnik Jakarta}

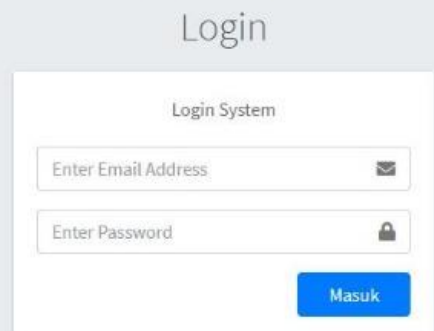

Keterangan Gambar:

Untuk menjalankan aplikasi Penggajian Karyawan Berbasis Web pada PO Arista Tehnik Jakarta user harus melakukan login, Memasukan Email dan Password yang telah dibuat oleh Administrator atau Pemilik.

\subsection{Implementasi Halaman Dashboard}
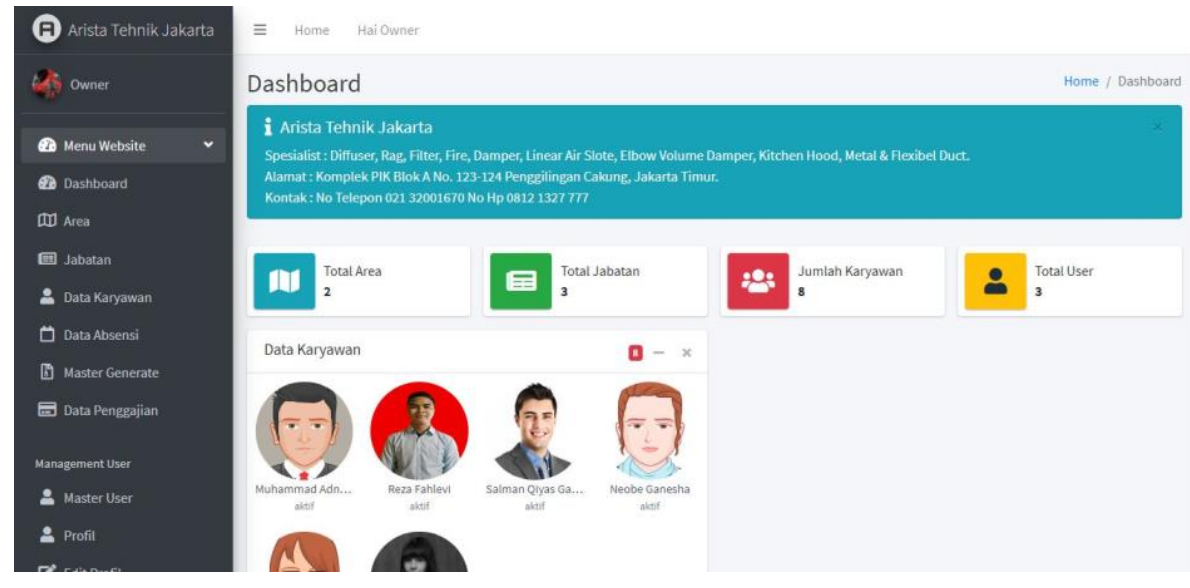

Gambar 4 Implementasi Halaman Dashboard

Keterangan Gambar:

Halaman Dashboard ini muncul setelah meng-input Email dan Password.
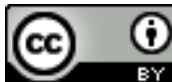

Ciptaan disebarluaskan di bawah Lisensi Creative Commons Atribusi 4.0 Internasional. http://journal.stmikjayakarta.ac.id/index.php/JMIJayakarta 
DOI: $10.52362 /$ jmijayakarta.v1i2.446

\subsection{Implementasi Halaman Data Absensi}

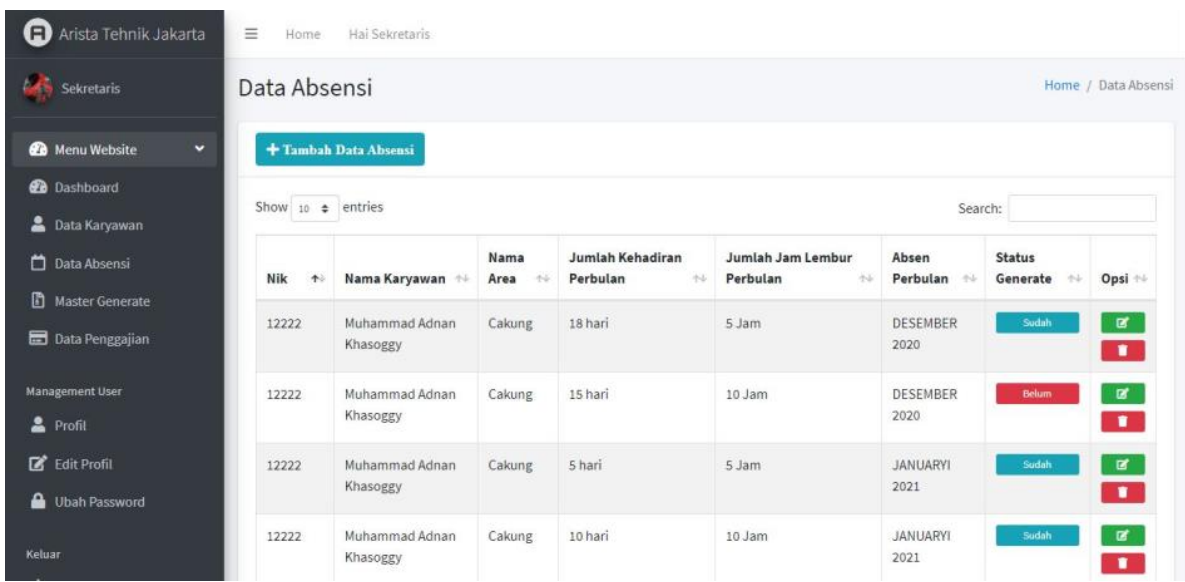

Gambar 5 Implementasi Halaman Data Absensi

\section{Keterangan Gambar:}

Halaman ini berisi informasi data absensi karyawan. Jika pada kolom Status Generate terdapat tulisan "Belum" berarti bahwa data tersebut belum di Generate.

\subsection{Implementasi Halaman Data Penggajian}

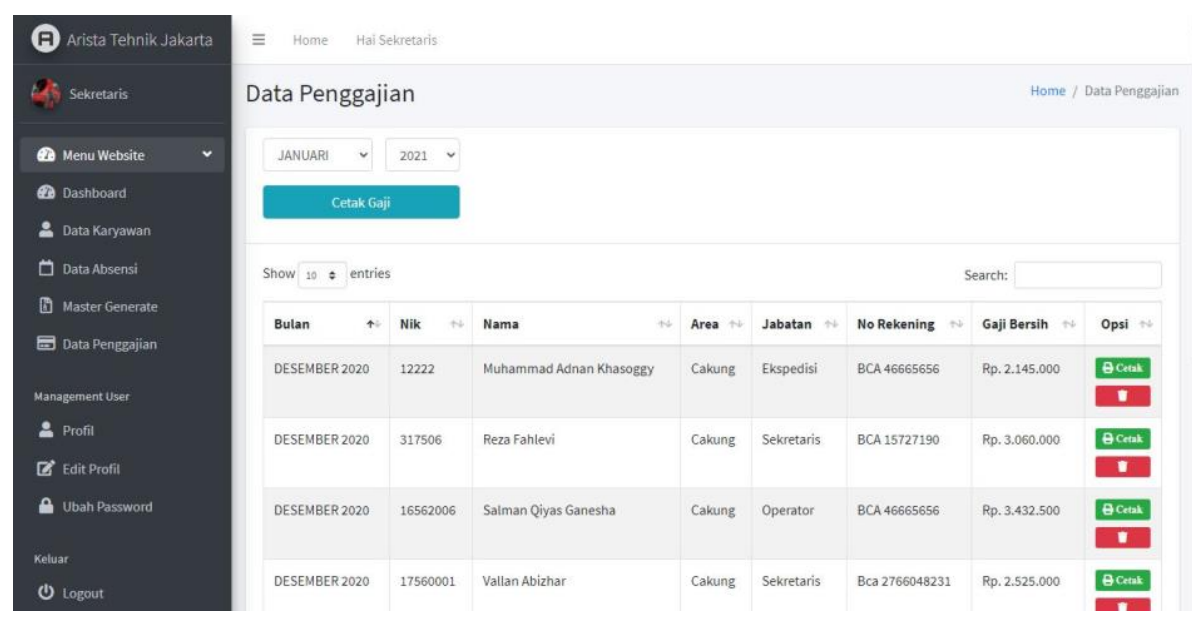

Gambar 6 Implementasi Halaman Data Penggajian

\section{Keterangan Gambar:}

Halaman ini berisikan hasil data yang sudah di Generate lalu muncul di menu Data penggajian ini. Pada halaman ini dapat melakukan mencetak laporan gaji berdasarkan bulan dan tahun dan mencetak slip gaji karyawan.

\section{KESIMPULAN}

Berdasarkan hasil analisa dan perumusan masalah yang telah dilakukan, maka penulis dapat menyimpulkan bahwa:

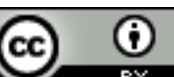


DOI: 10.52362/jmijayakarta.v1i2.446

1. Sistem penggajian yang sedang berjalan menggunakan penggajian manual bisa seringkali terjadi kesalahan. Setelah adanya sistem penggajian yang diusulkan dapat membantu mengatasi kesalahan penggajian manual.

2. Sistem penggajian yang sedang berjalan untuk menghitung gaji karyawan membutuhkan waktu yang cukup lama. Dengan Sistem penggajian yang diusulkan dapat memproses gaji dengan cepat dan akurat.

3. Sistem penggajian yang sedang berjalan laporan gaji bisa hilang karena tidak disimpan ke database. Dengan menggunakan sistem penggajian berbasis web dapat membuat laporan gaji karyawan dan slip gaji karyawan dengan cepat dan tersimpan pada database.

Adapun saran yang diusulkan oleh penulis setelah membuat sistem penggajian karyawan adalah:

1. Untuk pengembangan sistem selanjutnya perlu diperluas lagi atau memasukan ke jaringan internet (hosting), dalam arti semua karyawan bisa login untuk mengecek gaji tiap bulannya.

2. Untuk pengembangan sistem selanjutnya perlu menu hutang-piutang untuk catatan karyawan meminjam uang dengan perusahaan dan dipotong ketika gajian.

3. Untuk pengembangan sistem selanjutnya perlu sistem perhitungan memotong gaji jika karyawan terlambat masuk kerja atau absensi.

\section{REFERENSI}

[1] Chadzami, Royan. 2019. "Implementasi Sistem Penjualan Alat Olah Raga Menggunakan Basis Data Terdistribusi Dengan Metode Replikasi Asynchronous ( Studi Kasus Toko Yos Sport Yogyakarta )."

[2] Dede Firmansyah, Hamid Kurniawan, Widya Apriliah, Ilham Kurniawan,. 2020. "Penerapan Metode Waterfall Dalam Perancangan Sistem Informasi Penggajian Pada Smk Bina Karya Karawang.” Jurnal Interkom 14(4): 13-23.

[3] Destiningrum, Mara, and Qadhli Jafar Adrian. 2017. "Sistem Informasi Penjadwalan Dokter Berbassis Web Dengan Menggunakan Framework Codeigniter (Studi Kasus: Rumah Sakit Yukum Medical Centre)." Jurnal Teknoinfo 11(2): 30.

[4] Eka Wida Fridayanthie, Tias Mahdiati. 2016. "RANCANG BANGUN SISTEM INFORMASI PERMINTAAN ATK BERBASIS INTRANET (STUDI KASUS: KEJAKSAAN NEGERI RANGKASBITUNG)." X(2): 1-21.

[5] Hartoko, M Setiadi. 2016. "Rekrutmen Calon Karyawan Tetap (Studi Kasus Politeknik LP3I Jakarta Kampus Pasar Minggu).” Jurnal Akuntansi, Ekonomi dan Manajemen Bisnis Vol. 4(2): hlm. 123.

[6] Hasugian, Penda Sudarto. 2018. "Perancangan Website Sebagai Media Promosi Dan Informasi." Journal Of Informatic Pelita Nusantara 3(1): 82-86.

[7] Josi, Ahmat. 2017. "Penerapan Metode Prototyping Dalam Membangun Website Desa (Studi Kasus Desa Sugihan Kecamatan Rambang).” Jti 9(1): 50-57.

[8] Maimunah, Maimunah, Ilamsyah Ilamsyah, and Muhamad Ilham. 2016. "Rancang Bangun Aplikasi Penjualan Furniture Online Pada Mitra Karya Furniture." CSRID (Computer Science Research and Its Development Journal) 8(1): 25.

[9] Maimunah, Maimunah, Supra Singgih, and Anwar Supriyadi. 2017. "Rancang Bangun Sistem Sms Gateway Sebagai Fasilitas Permohonan Cuti Karyawan.” Journal CERITA 3(1): 36-48.

[10] Nurul Hidayat, Fery Wongso, Bero Usada. 2020. "Perancangan Sistem Informasi Persediaan Barang Secara Online Di Paragon Komputer Pekanbaru Berbasis Web. Skripsi, Pekanbaru: Program Studi Sistem Informasi, Sekolah Tinggi Manajemen Informatika Dan Komputer.” Jurnal Ilmu Komputer dan Bisnis 11(8): 1689-99.

[11] Sari, Lia Kumala, and Jaka Permadi. 2018. “Aplikasi Penggajian Berbasis Web PT. Tirta Sukses Perkasa." Jurnal Sains dan Informatika 4(1): 13-19.

[12] Sidik, Achmad, Arnie Retno, and alfia ria Anggraeni. 2018. "Perancangan Sistem Informasi ERecruitment Guru Studi Kasus Di SMK Kusuma Bangsa." Sisfotek Global 8(1): 69-74. 
DOI: 10.52362/jmijayakarta.v1i2.446

[13] Sihotang, Hengki Tamando. 2019. "Sistem Informasi Pengagendaan Surat Berbasis Web Pada Pengadilan Tinggi Medan.” 3(1): 6-9.

[14] Soleh, Oleh, Futri Yunita Aulia, and Anis Khoirotun Nisa. 2018. "Aplikasi Monitoring Jumlah Bibit Tanaman Menggunakan Analisa Balance Score Card Pada Uptd Tpa Rawa Kucing Kota Tangerang." : 127-32.

[15] Widyawati, Efy. 2016. "Rancang Bangun Aplikasi Kependudukan Berbasis Web Di Desa Kedungrejo Waru-Sidoarjo." Jurnal Manajemen Informatika 6(1).

[23] Benni Triyono, Sri Purwanti, Verdi Yasin (2017) "Rekayasa Perangkat Lunak Sistem Informasi Pengiriman Dan Penerimaan Surat Atau Paket Berbasis Web", Journal of Information System, Applied, Management, Accounting and Research, e-ISSN: 2598-8719. p-ISSN: 2598-8700.Vol.1 No.1 (30 Desember 2017) p46-53

http://journal.stmikjayakarta.ac.id/index.php/jisamar/article/view/12

[24] Verdi Yasin, Muhammad Zarlis, Mahyuddin K.M. Nasution (2018) "Filsafat Logika Dan Ontologi Ilmu Komputer", Journal of Information System, Applied, Management, Accounting and Research, e-ISSN: 2598-8719. p-ISSN: 2598-8700.Vol.2 No.2 (19 Juni 2018) p68-75 http://journal.stmikjayakarta.ac.id/index.php/jisamar/article/view/39

[25] Julinda Maya Paramudita, Verdi Yasin (2019) "Perancangan Aplikasi Sistem Penyewaan Alat Berat ", Journal of Information System, Applied, Management, Accounting and Research, e-ISSN: 25988719. p-ISSN: 2598-8700.Vol.3 No.1 (20 Februari 2019) p23-29

http://journal.stmikjayakarta.ac.id/index.php/jisamar/article/view/73

[26] Muryan Awaludin, Verdi Yasin (2020) "Application Of Oriented Fast And Rotated Brief (Orb) And Bruteforce Hamming In Library Opencv For Classification Of Plants", Journal of Information System, Applied, Management, Accounting and Research, e-ISSN: 2598-8719. p-ISSN: 25988700.Vol.4 No.3 (14 Agustus 2020) p51-59

http://journal.stmikjayakarta.ac.id/index.php/jisamar/article/view/247

[27] Ifan Junaedi, Dimas Abdillah, Verdi Yasin (2020) "Analisis Perancangan Dan Pembangunan Aplikasi Business Intelligence Penerimaan Negara Bukan Pajak Kementerian Keuangan RI”, Journal of Information System, Applied, Management, Accounting and Research, e-ISSN: 2598-8719. pISSN: 2598-8700.Vol.4 No.3 (14 Agustus 2020) p88-101 http://journal.stmikjayakarta.ac.id/index.php/jisamar/article/view/249 